\title{
Rhodium(II) Catalyzed Cyclopropanation/Cycloaddition Reactions of the Bis(diazo)piperidin-2-one System
}

\author{
Sara A. Bonderoff and Albert Padwa*: \\ Department of Chemistry, Emory University, Atlanta, GA 30322, USA \\ Phone: 404-727-0283; fax: 404-727-6586; email: chemap@emory.edu
}

Keywords: Rhodium(II), catalysis, carbenoid, cyclopropanation, dipolar cycloaddition, bis(diazo)indolin-2-one, cascade

Abstract: Bis(diazo)piperidin-2-ones that are devoid of a donor substituent in the 4position undergo a one-pot cyclopropanation/cascade dipole formation/cycloaddition reaction to produce novel azapolycycles.

Tandem reactions represent an efficient protocol for the construction of multiple $\mathrm{C}-\mathrm{C}$ bonds in a single operation. ${ }^{1}$ Recently, we have reported on the tandem $\mathrm{Rh}$ (II)catalyzed reactions of the bis(diazo)indolin-2-one system (1). ${ }^{2}$ The carbenoid intermediate derived from the more reactive 3-diazo group present in $\mathbf{1}$ undergoes either an initial cyclopropanation or else insertion into a XH-bond (i.e. ROH or RNHR). This step is then followed by formation of an acyclic metallocarbenoid which subsequently results in dipole formation and a final dipolar cycloaddition in the presence of a dipolarophile to give adducts $\mathbf{2}$ or $\mathbf{3}$ (Scheme 1). The events occur selectively, and in a predictable manner. ${ }^{3}$ Metallo-carbenoids derived from the $\mathrm{Rh}(\mathrm{II})$-catalyzed reaction of $\alpha$ diazo carbonyl compounds are generally classified into various reaction types based on the nature of the substituents flanking the carbenoid center. Most typically, electron donor or acceptor groups are employed, with donor/acceptor (D/A) and acceptor/acceptor (A/A) combinations being most frequently used. ${ }^{4}$

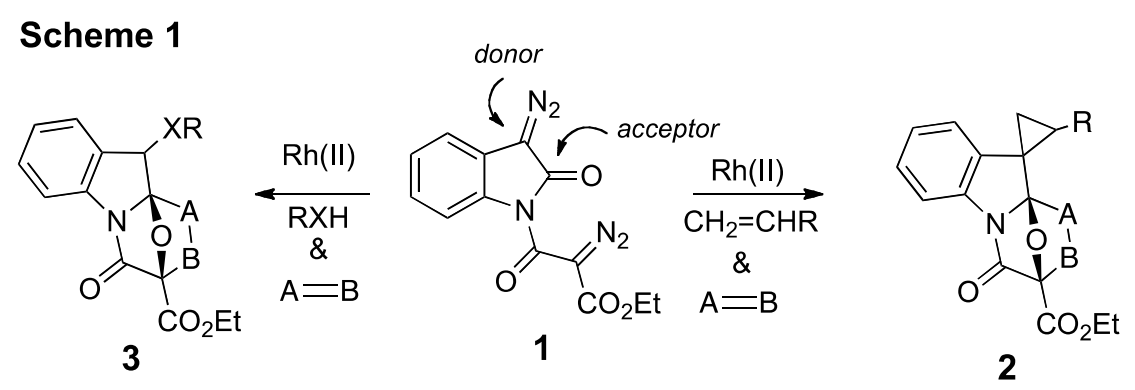

3-Diazopiperidinones represent an uncommon class of $\alpha$-diazo carbonyl compounds and there are very few examples in the literature of metallocarbenoidmediated reactions of these diazo-substituted lactams. 5 The 4-substituent group present in the few known examples is often a carbonyl or else a fused aromatic ring which changes the nature of the metallocarbenoid from an acceptor to an acceptor/acceptor or donor/acceptor system. The diazo group present in the 3-diazopiperidin-2-one system (i.e. 5) contains only a single $\alpha$-electron withdrawing substituent and should exhibit different reactivity from the diazo functionality present in the bis(diazo)indolin-2-one 
system (1). ${ }^{2}$ However, the reactivity differences in the acceptor, acceptor/acceptor system should still permit this type of tandem process to occur. In an earlier publication, Muthusamy and Srinivasan reported an example of a formal $\mathrm{CH}$ insertion of a bis(diazo) lactam followed by an intramolecular 1,3-dipolar cycloaddition thereby providing promising precedent for the proposed cascade sequence of reactions for the bis(diazo)piperidin-2-one system (4). ${ }^{5}$ In this communication, we describe an extension of the scope of the one-pot cyclopropanation/dipolar cycloaddition to bis(diazo)substituted piperidinones of type 4 .

Ethyl 2-diazo-3-(3-diazo-2-oxopiperidin-1-yl)-3-oxopropanoate (4) was synthesized by acylation of 3-diazo-2-piperidone ${ }^{6}$ with ethyl 2-diazomalonyl chloride. We anticipated that the cyclic diazo moiety would react with the rhodium (II) catalyst as the first step in our proposed tandem cascade sequence. Prior to assessing the reactivity of bis(diazo) 4, we conducted a brief study of the behavior of this portion of our model system in the absence of the ethyl 2-diazomalonyl substituent in order to avoid potential complication by the second diazo group. To this end, 3-diazo-2-piperidinone was converted to the Boc-protected piperidinone 5 under standard conditions.

Since cyclopropanation corresponds to one of the most important reactions of $\alpha$ diazocarbonyl compounds, ${ }^{7}$ we first explored the reaction of $\mathbf{5}$ with several alkenes. The Boc-3-diazopiperidone 5 was added over $1 \mathrm{~h}$ to 3 equiv. of styrene in $\mathrm{DCM}$ at $-40^{\circ} \mathrm{C}$ in the presence of catalytic $\mathrm{Rh}_{2}(\mathrm{OAc})_{4}$, providing cyclopropane 6 in $42 \%$ yield as a single diastereomer. When $\mathrm{Rh}_{2}(\mathrm{OPiv})_{4}$ was used instead of $\mathrm{Rh}_{2}(\mathrm{OAc})_{4}$, the yield of phenylcyclopropane 6 was substantially enhanced (i.e. 87\%). Since toluene was previously found to be a better solvent than dichloromethane for the dipolar cycloaddition reaction that we intended to combine with the cyclopropanation reaction, we screened this solvent for the cyclopropanation reaction. We noted, however, that on changing the reaction solvent from DCM to toluene, the yield of phenylcyclopropane $\mathbf{6}$ derived from $\mathbf{5}$ dropped to $48 \%$.

\section{Scheme 2}

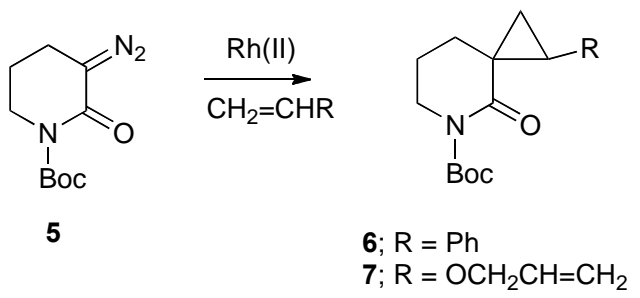

\begin{tabular}{llllll}
\hline$\#$ & $\mathrm{R}$ & $\begin{array}{l}\text { Temp } \\
\left({ }^{\circ} \mathrm{C}\right)\end{array}$ & Catalyst & Solvent & $\%$ \\
\hline 1 & $\mathrm{Ph}$ & -40 & $\mathrm{Rh}_{2}(\mathrm{OAc})_{4}$ & DCM & 42 \\
2 & $\mathrm{Ph}$ & -40 & $\mathrm{Rh}_{2}(\mathrm{OPiv})_{4}$ & DCM & 87 \\
3 & $\mathrm{Ph}$ & -40 & $\mathrm{Rh}_{2}(\mathrm{OPiv})_{4}$ & Tolue & 48 \\
4 & $\mathrm{OCH}_{2} \mathrm{CH}=\mathrm{CH}_{2}$ & -40 & $\mathrm{Rh}_{2}(\mathrm{OPiv})_{4}$ & DCM & 61 \\
5 & $\mathrm{OCH}_{2} \mathrm{CH}=\mathrm{CH}_{2}$ & -78 & $\mathrm{Rh}_{2}(\mathrm{OPiv})_{4}$ & DCM & 57 \\
6 & OTIPS & -40 & $\mathrm{Rh}_{2}(\mathrm{OPiv})_{4}$ & DCM & 0 \\
& & & & & \\
\hline
\end{tabular}

Because of this significant solvent effect, DCM was employed for the cyclopropanation of $\mathbf{5}$ with allyl vinyl ether. The reaction proceeded in $61 \%$ yield under these reaction conditions, with complete chemoselectivity for cyclopropanation at the electron-rich vinyl ether. The yield of cyclopropane 7 did not improve when the reaction was conducted at $-78^{\circ} \mathrm{C}$. In contrast, the bulky (hexa-1,5-dien-2-yloxy)triisopropylsilane was not a suitable substrate for cyclopropanation at $-40{ }^{\circ} \mathrm{C}$, or even when the reaction was carried out at ambient temperature.

At this point we went on to study the $\mathrm{Rh}$ (II)-catalyzed reaction of bis(diazo) piperidone $\mathbf{4}$. Reaction of $\mathbf{4}$ with styrene or allyl vinyl ether proceeded cleanly by TLC 
analysis of the reaction mixture. The resulting products 8 and $\mathbf{9}$ were obtained as single diastereomers but were not stable to workup or chromatographic purification, and the phenyl and allyloxy-substituted cyclopropanes could only be isolated in low yield (i.e. $25 \%$ and $10 \%$ respectively). Addition of thiourea to the reaction mixture so as to remove the catalyst prior to isolation of the resulting cyclopropanes did not improve the overall yield. ${ }^{8}$ Also, cyclopropanation of $\mathbf{4}$ with styrene using benzene as the solvent did not significantly alter the amount of the resulting cyclopropane products formed. However, by TLC analysis of these reactions, it appeared that the cyclopropanation was proceeding cleanly, despite the poor isolated yields.

\section{Scheme 3}<smiles>CCOC(=O)C(=O)N1CCCC(=N)C1=O</smiles>

4

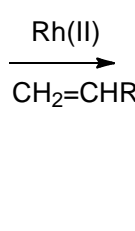

9; $\mathrm{R}=\mathrm{OCH}_{2} \mathrm{CH}=\mathrm{CH}_{2}$

A subsequent study using $\mathbf{8}$ under $\mathrm{Rh}(\mathrm{II})$-catalysis with added $\mathrm{N}$-phenylmaleimide gave cycloadduct $\mathbf{1 1}$ in $70 \%$ yield as a 1.4:1 mixture of diastereomers and presumably occurs by initial dipole formation to produce isomünchnone $\mathbf{1 0}$ followed by a subsequent dipolar cycloaddition with the added dipolarophile (Scheme 4). ${ }^{9}$

\section{Scheme 4}

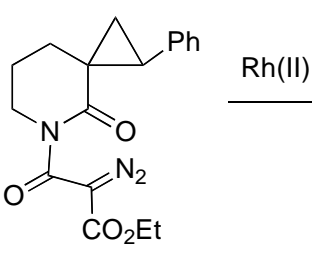

8

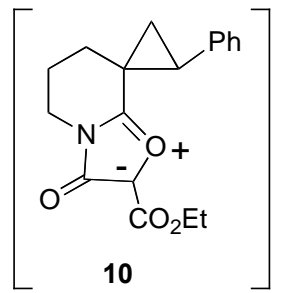

10

$$
\underset{\text { maleimide }}{\stackrel{N \text {-phenyl }}{\longrightarrow}}
$$<smiles>CCOC(=O)C12OC34C(CC1C(c1ccccc1)C3C1C(=O)N(c3ccccc3)C(=O)C14)C2=O</smiles>

11

Considering the success of the Rh(II)-catalyzed cycloaddition of $\mathbf{8}$ with $\mathrm{N}$-phenyl maleimide, it seemed plausible that the overall yield might be improved if the cyclopropanation and cycloaddition steps were telescoped together so as to avoid isolation of the problematic cyclopropanated diazo compound intermediate. Thus, styrene was first allowed to undergo cyclopropanation with bis(diazo) $\mathbf{4}$ in benzene at

Scheme 5

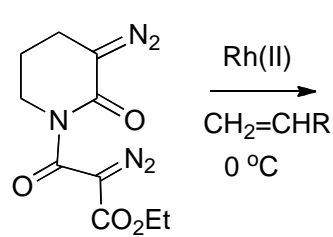

4

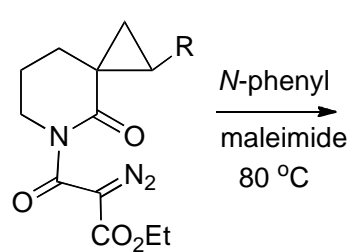

8; $\mathrm{R}=\mathrm{Ph}$

9; $\mathrm{R}=\mathrm{OCH}_{2} \mathrm{CH}=\mathrm{CH}_{2}$

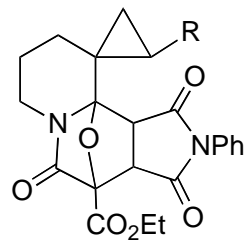

11; $\mathrm{R}=\mathrm{Ph} ; 30 \%$

12; $\mathrm{R}=\mathrm{OCH}_{2} \mathrm{CH}=\mathrm{CH}_{2} ; 35 \%$ 
$0{ }^{\circ} \mathrm{C}$, and then 2 equiv. of $N$-phenylmaleimide was added, and the reaction mixture was heated to reflux. Cycloadduct 11 was isolated in 30\% yield. When the reaction sequence was carried out with ethyl vinyl ether in place of styrene, cycloadduct $\mathbf{1 2}$ was obtained in $35 \%$ yield (Scheme 5).

Although benzene appears to be an excellent solvent for the dipole formation/ cycloaddition cascade portion of the reaction sequence, as demonstrated using Bocdiazopiperidinone 5, dichloromethane is the preferred solvent for cyclopropanation of the diazopiperidone. We reasoned that the cyclopropanation reaction of 9 could be done in dichloromethane, and then benzene would be added as a cosolvent to improve the yield of the subsequent cycloaddition step. With this in mind, ethyl vinyl ether was cyclopropanated using bis(diazo) 4 in dichloromethane at $-40{ }^{\circ} \mathrm{C}$, and then a mixture of DMAD and benzene was added and the solution was heated to reflux so as to effect dipole formation/dipolar cycloaddition. Cycloadduct 13 was formed in 44\% yield as a 2.7:1 mixture of diastereomers. More gratifyingly, bis(diazo) 4 underwent the telescoped process using a mixture of styrene and methyl acrylate to give a $70 \%$ yield of cycloadduct $\mathbf{1 4}$ as a mixture of three diastereomers (Scheme 6).

\section{Scheme 6}

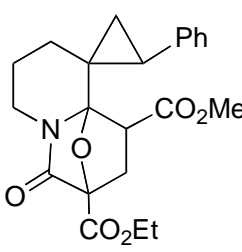

$14 ; 70 \%$

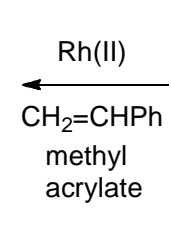

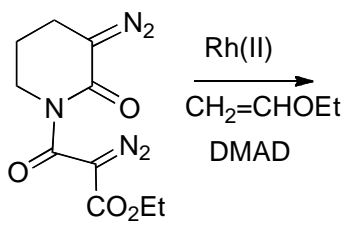

4

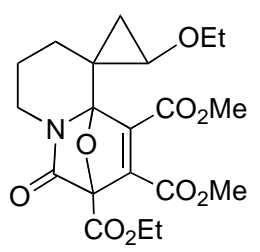

$13 ; 44 \%$

In conclusion, we have demonstrated that cyclic $\alpha$-diazoamides lacking a donor substituent in the 4-position can undergo a one-pot cyclopropanation/cascade dipole formation-cycloaddition reaction to produce novel azapolycycles. The use of vinyl ethers and styrene as substrates for the cyclopropanation reaction was examined and several dipolarophiles were studied and resulted in the formation of azapolycycles as a mixture of diastereoisomers in moderate to good yield. Unlike the previously studied bis(diazo)indolin-2-one system (1), the piperidone carbenoid system required that the cyclopropanation be carried out at a lower temperature before heating the initially formed cyclopropane with an added dipolarophile so as to produce the final cycloadduct. Further studies on an intramolecular variant of this reaction will be reported in due course.

* This article is dedicated to the memory of Professor Harry H. Wasserman, Yale University, New Haven (December 1, 1920 - December 29, 2013).

\section{Acknowledgement}

We appreciate the financial support provided by the National Science Foundation (CHE1057350).

\section{References}


1. (a) Tietze, L. F. Chem. Rev. 1996, 96,115. (b) Tietze, L. F.; Beifuss, U. Angew. Chem., Int. Ed. Engl. 1993, 32,131. (c) Ho, T. L. Tandem Organic Reactions; Wiley: New York, NY, 1992; (d) Bunce, R. A. Tetrahedron 1995, 51, 13103; (e) Parsons, P. J.; Penkett, C. S.; Shell, A. J. Chem. Rev. 1995, 95, 195.

2. (a) Bonderoff, S. A.; Padwa, A. Org. Lett. 2013, 15, 4114. (b) Li, H.; Bonderoff, S. A.; Cheng, B.; Padwa, A. J. Org. Chem. 2014, 79, 392.

3. (a) Padwa, A. Chem. Soc. Rev. 2009, 38, 3072. (b) Padwa, A. Tetrahedron 2011, 67, 8057.

4. (a) Hansen, J., H.; Parr, B., T.; Pelphrey, P.; Jin, Q.; Autschbach, J.; Davies, H., M., L. Angew. Chem., Int. Ed. 2011, 50, 2544. (b) Pelphrey, P.; Hansen, J.; Davies, H. M. L. Chem. Sci. 2010, 1, 254.

5. Muthusamy, S.; Srinivasan, P. Tetrahedron 2009, 65, 1567.

6. (a) Hutchinson, I. S.; Matlin, S. A.; Mete, A. Tetrahedron 2002, 58, 3137. (b) Harrison, R.; Mete, A.; Wilson, L. Tetrahedron Lett. 2003, 44, 6621.

7. (a) Doyle, M., P.; McKervey, M., A.; Ye, T. Modern Catalytic Methods for Organic Synthesis with Diazo Compounds; Wiley: New York, NY, 1998. (b) Ye, T.; McKervey, M., A. Chem. Rev. 1994, 94, 1091. (c) Zhang, Z.; Wang, J. Tetrahedron 2008, 64, 6577.

8. Osman, A., Method to Treat Rhodium-Containing Solutions. European Patent 0,354,413,A1, July 27, 1989.

9. Padwa, A.; Hornbuckle, S. F. Chem. Rev. 1991, 91, 263. (b) Padwa, A.; Weingarten, M. D. Chem. Rev. 1996, 96, 223. 


\section{Graphical Abstract}

To create your abstract, type over the instructions in the template box below.

Rhodium(II) Catalyzed Cyclopropanation/Cycloaddition Leave this area blank for abstract info. Reactions of the Bis(diazo)piperidin-2-one System Sara A. Bonderoff and Albert Padwa*: Department of Chemistry, Emory University, Atlanta, GA 30322, USA

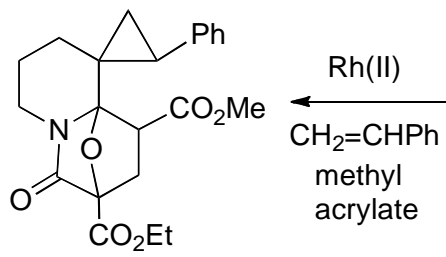<smiles>CCOC(=O)C(=O)N1CCCC(=N)C1=O</smiles><smiles>CCOc1ccccc1</smiles>

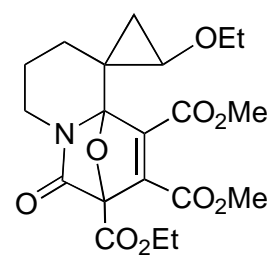

